\title{
REVIEW
}

\section{The Role of Panobinostat Plus Bortezomib and Dexamethasone in Treating Relapsed or Relapsed and Refractory Multiple Myeloma: A European Perspective}

Jesus F. San-Miguel · Hermann Einsele · Philippe Moreau

Received: August 1, 2016 / Published online: September 27, 2016

(C) The Author(s) 2016. This article is published with open access at Springerlink.com

\begin{abstract}
Panobinostat is an oral pan-histone deacetylase inhibitor developed by Novartis. Panobinostat acts via epigenetic modification and inhibition of the aggresome pathway. In August 2015, the European Commission authorized panobinostat for use in combination with bortezomib and dexamethasone for the treatment of relapsed or relapsed and refractory multiple myeloma (MM) in patients who have received $\geq 2$ prior regimens including bortezomib and an immunomodulatory drug. In January 2016, the National Institute for Health and Care Excellence recommended panobinostat for use in the same combination and patient population. The authorization and
\end{abstract}

Enhanced content To view enhanced content for this article go to http://www.medengine.com/Redeem/ A1E6F06042D48AA2.

J. F. San-Miguel ( $\square)$

Clínica Universidad de Navarra, CIMA, IDISNA, Pamplona, Spain

e-mail: sanmiguel@unav.es

H. Einsele

Medizinische Klinik und Poliklinik II, University of

Würzburg, Würzburg, Germany

P. Moreau

University Hospital of Nantes, Nantes, France recommendation were based on results from the pivotal phase 3 PANORAMA 1 (NCT01023308) clinical trial, which demonstrated an improvement in median progression-free survival of 7.8 months for the three-drug combination compared with placebo plus bortezomib and dexamethasone in this patient population. This review will discuss the current treatment landscape for relapsed/ refractory $\mathrm{MM}$, the mechanism of action of panobinostat, clinical data supporting the European authorization, concerns about safety and strategies for mitigating toxicity, and how panobinostat fits into the current MM landscape in Europe.

Funding: Editorial support, funded by Novartis Pharmaceuticals.

Keywords: Multiple myeloma; Oncology; Panobinostat; Relapsed; Relapsed and refractory

\section{INTRODUCTION}

Multiple myeloma (MM) is a hematologic disorder characterized by clonal proliferation of malignant plasma cells in the bone marrow 
that overproduce abnormal monoclonal proteins [1]. It can be classified as asymptomatic or active, based on the presence of MM biomarkers (clonal bone marrow plasma cells, serum free light chain ratio, and focal lesions) or CRAB criteria (disease-associated organ damage that includes hypercalcemia, renal insufficiency, anemia, and bone disease) [2]. MM tends to present in older patients, with the median age at diagnosis being $\approx 70$ years [1]. Therefore, the incidence of MM is expected to increase as the population ages, as seen in a recent European survey [3]. In this survey, there were $\approx 39,000$ cases of newly diagnosed MM in 2012 [4], with the incidence expected to rise by $30 \%$ by 2035 [3].

MM remains an incurable disease. Over the past decade, breakthroughs in myeloma therapy, particularly the introduction of proteasome inhibitors (PIs) and immunomodulatory drugs (IMiDs) and the use of autologous stem cell transplantation, have vastly improved patient outcomes $[5,6]$. However, due to the clonal nature of the disease, the majority of patients will relapse after currently available therapies, and with each successive relapse, the prognosis worsens $[7,8]$. Therefore, an unmet need exists for agents with new mechanisms of action that can overcome disease resistance to current therapeutic regimens.

Panobinostat, a first-in-class pan-deacetylase inhibitor (DACi), was recently authorized by the European Commission (EC) and recommended by the National Institute for Health and Care Excellence (NICE) in combination with bortezomib and dexamethasone for the treatment of patients with $\mathrm{MM}$ who have received $\geq 2$ prior therapeutic regimens including bortezomib and an IMiD. This review will discuss the current treatment landscape for relapsed/refractory MM (RRMM), the unique mechanism of action of panobinostat, clinical data supporting the EC authorization of panobinostat in patients with relapsed or RRMM who have received $\geq 2$ prior therapeutic regimens, concerns about safety and strategies for mitigating toxicity, and how this novel therapeutic fits into the current MM treatment landscape in Europe.

\section{Compliance with Ethics Guidelines}

This article is based on previously conducted studies, and does not involve any new studies of human or animal subjects performed by any of the authors.

\section{TREATMENT OF RRMM IN EUROPE: THE CURRENT THERAPEUTIC LANDSCAPE}

Although, as mentioned, major advances have been made in the treatment of patients with MM [5, 8], the majority of patients will eventually relapse after or become refractory to the available therapies $[7,8]$. However, the majority of agents currently authorized by the $\mathrm{EC}$ for the treatment of $\mathrm{MM}$ are derived from just two drug classes, PIs and IMiDs (Table 1). The two approved PIs are bortezomib (authorized April 26, 2004) and carfilzomib (authorized November 19, 2015). Authorized IMiDs include lenalidomide (June 14, 2007), thalidomide (April 16, 2008), and pomalidomide (August 5, 2013); however, thalidomide is authorized only in patients with untreated myeloma [9]. Other agents include classical chemotherapeutics, such as doxorubicin, cyclophosphamide, and bendamustine-as possible salvage therapies or in combination with novel agents-as well as 
Table 1 Agents currently authorized by the European Commission

\begin{tabular}{|c|c|c|c|c|}
\hline Agent & $\begin{array}{l}\text { Trade } \\
\text { name }\end{array}$ & MOA & European Commission indication & $\begin{array}{l}\text { Date of } \\
\text { authorization }\end{array}$ \\
\hline Doxorubicin & Caelyx $^{\circledR}$ & Anthracycline & $\begin{array}{l}\text { Treatment of patients with progressive } M M \text { who have } \\
\text { received } \geq 1 \text { previous therapeutic regimen and have } \\
\text { undergone or are unsuitable for bone marrow } \\
\text { transplant }\end{array}$ & 21 June 1996 \\
\hline $\begin{array}{l}\text { Interferon } \\
\alpha-2 b\end{array}$ & Intron $A^{\circledR}$ & $\begin{array}{c}\text { Recombinant } \\
\text { cytokine }\end{array}$ & $\begin{array}{l}\text { As maintenance therapy in patients with } \mathrm{MM} \text { who have } \\
\text { achieved an objective response ( }>50 \% \text { reduction in } \\
\text { M-protein) following induction chemotherapy }\end{array}$ & $\begin{array}{l}09 \text { March } \\
2000\end{array}$ \\
\hline Bortezomib & Velcade $^{\circledR}$ & $\begin{array}{c}\text { Proteasome } \\
\text { inhibitor }\end{array}$ & $\begin{array}{l}\text { Treatment of patients with MM } \\
\text { Who are previously untreated and not eligible for } \\
\text { high-dose chemotherapy and ASCT; in combination } \\
\text { with melphalan and prednisone } \\
\text { Who are previously untreated and are going to receive } \\
\text { high-dose chemotherapy and ASCT; in combination } \\
\text { with dexamethasone or thalidomide and } \\
\text { dexamethasone } \\
\text { Who have progressed following } \geq 1 \text { prior therapeutic } \\
\text { regimen and have received or are ineligible to receive } \\
\text { ASCT; either as monotherapy or in combination with } \\
\text { pegylated liposomal doxorubicin or dexamethasone }\end{array}$ & 26 April 2004 \\
\hline Lenalidomide & Revlimid $^{\circledR}$ & IMiD & $\begin{array}{l}\text { Treatment of patients with } \mathrm{MM} \\
\text { Who are previously untreated and are not eligible for } \\
\text { ASCT } \\
\text { Who have received } \geq 1 \text { prior antimyeloma therapy; in } \\
\text { combination with dexamethasone }\end{array}$ & 14 June 2007 \\
\hline Thalidomide & Thalomid $^{\circledR}$ & IMiD & $\begin{array}{l}\text { Treatment of patients with } \mathrm{MM} \text { who are previously } \\
\text { untreated and aged } \geq 65 \text { years or ineligible for } \\
\text { high-dose chemotherapy; in combination with } \\
\text { melphalan and prednisone }\end{array}$ & 16 April 2008 \\
\hline Pomalidomide & Imnovid $^{\circledR}$ & IMiD & $\begin{array}{l}\text { Treatment of patients with relapsed and refractory } M M \\
\text { who have received } \geq 2 \text { prior regimens including } \\
\text { bortezomib and lenalidomide and have demonstrated } \\
\text { disease progression on the last therapy; in } \\
\text { combination with dexamethasone }\end{array}$ & $\begin{array}{c}05 \text { August } \\
2013\end{array}$ \\
\hline Panobinostat & Farydak $^{\circledR}$ & $\begin{array}{l}\text { Pan-deacetylase } \\
\text { inhibitor }\end{array}$ & $\begin{array}{l}\text { Treatment of patients with relapsed or relapsed and } \\
\text { refractory } \mathrm{MM} \text { who have received } \geq 2 \text { prior regimens } \\
\text { including bortezomib and an } \mathrm{IMiD} \text {; in combination } \\
\text { with bortezomib and dexamethasone }\end{array}$ & $\begin{array}{l}28 \text { August } \\
2015\end{array}$ \\
\hline
\end{tabular}


Table 1 continued

\begin{tabular}{|c|c|c|c|c|}
\hline Agent & $\begin{array}{l}\text { Trade } \\
\text { name }\end{array}$ & MOA & European Commission indication & $\begin{array}{l}\text { Date of } \\
\text { authorization }\end{array}$ \\
\hline Carfilzomib & Kyprolis $^{\circledR}$ & $\begin{array}{c}\text { Proteasome } \\
\text { inhibitor }\end{array}$ & $\begin{array}{l}\text { Treatment of patients with } \mathrm{MM} \text { who have received } \geq 1 \\
\text { prior therapy; in combination with lenalidomide and } \\
\text { dexamethasone }\end{array}$ & $\begin{array}{l}19 \text { November } \\
2015\end{array}$ \\
\hline Elotuzumab & Empliciti $^{\mathrm{TM}}$ & $\begin{array}{l}\text { Anti-SLAMF7 } \\
\text { monoclonal } \\
\text { antibody }\end{array}$ & $\begin{array}{l}\text { Treatment of patients with } \mathrm{MM} \text { who have received } \geq 1 \\
\text { prior therapy; in combination with lenalidomide and } \\
\text { dexamethasone }\end{array}$ & 11 May 2016 \\
\hline Daratumumab & Darzalex $^{\mathrm{TM}}$ & $\begin{array}{l}\text { Anti-CD38 } \\
\text { monoclonal } \\
\text { antibody }\end{array}$ & $\begin{array}{l}\text { Treatment of patients with RRMM whose prior therapy } \\
\text { included a PI and an IMiD and who have } \\
\text { demonstrated disease progression on the last therapy; } \\
\text { monotherapy }\end{array}$ & 20 May 2016 \\
\hline
\end{tabular}

$\overline{A S C T}$ autologous stem cell transplant, IMiD immunomodulatory drug, $M O A$ mechanism of action, $M M$ multiple myeloma, RRMM relapsed/refractory multiple myeloma, SLAMF7 signaling lymphocytic activation molecule F7, PI proteasome inhibitors

the recently approved monoclonal antibodies elotuzumab and daratumumab.

\section{PIs}

It is believed that MM cells are much more sensitive to proteasome inhibition than normal cells due to the aberrant production of abnormal and mutant proteins [10]. Blockade of the proteasome leads not only to an unfolded protein stress response within the cell [11], but can also directly influence expression of proteins normally degraded through active proteasomes, including those involved in apoptosis, cell cycle progression, and activation of the transcriptional factor NFKB. Therefore, inhibiting the proteasome can lead to apoptosis and inhibition of proliferation $[12,13]$.

\section{Bortezomib}

Bortezomib was the first PI to be authorized for the treatment of MM by the EC (Table 1).
Bortezomib is a boronic acid analog that reversibly binds and inhibits the chymotryptic activity of the $20 \mathrm{~S}$ proteasome subunit [14]. In the phase 3 APEX trial (NCT00048230), bortezomib was superior to dexamethasone for the treatment of MM that had relapsed after 1-3 previous therapies (Table 2) [15]. Patients treated with bortezomib had a significant increase in overall response rate (ORR; 38\% vs $18 \% ; P<0.001)$, a significantly prolonged time to progression (TTP; 6.2 vs 3.5 months; $P<0.001)$, and a significant overall survival (OS) benefit ( $80 \%$ vs $66 \%$ at 1 year; $P=0.003$ ) (Table 2).

\section{Carfilzomib}

Carfilzomib, a second-generation PI, is a tetrapeptide epoxyketone analog of epoxomicin that primarily inhibits the chymotrypsin site of the $20 \mathrm{~S}$ subunit of the proteasome but may also act upon the trypsin-like and caspase-like sites at high concentrations [12, 16]. Carfilzomib binds 


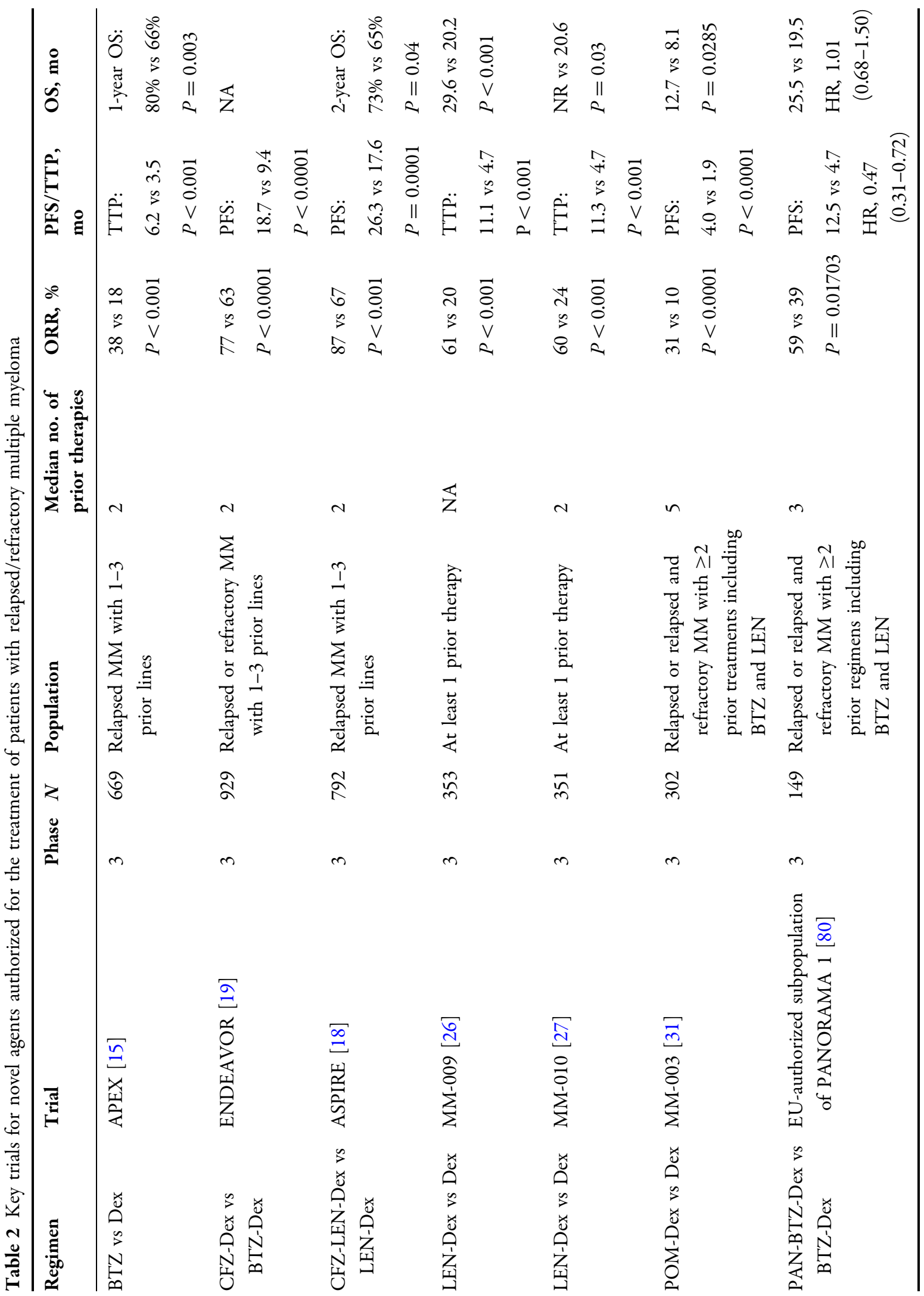




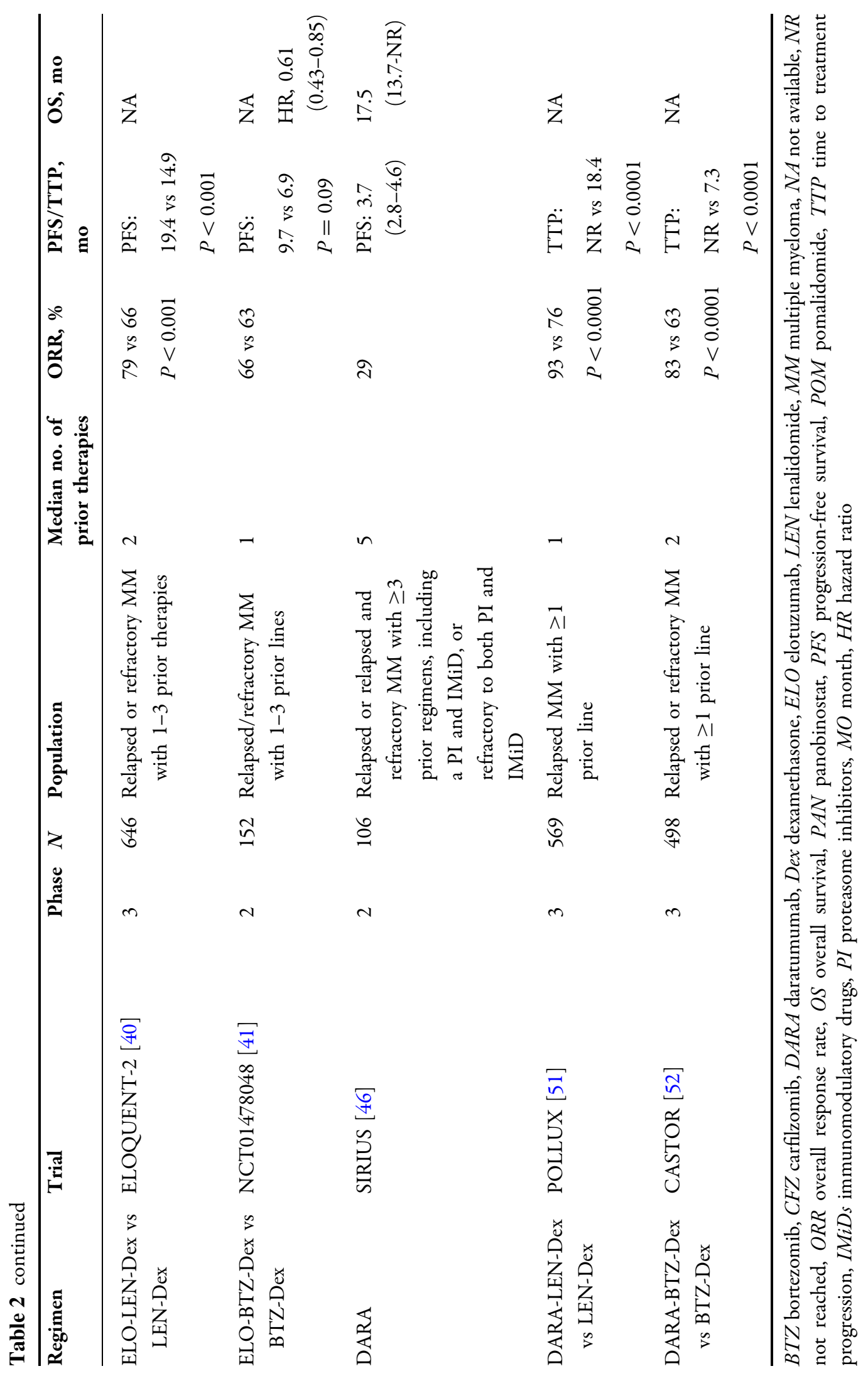


irreversibly to the proteasome and, compared with bortezomib, appears to be a more specific PI, leading to diminished off-target effects $[12,16,17]$. In the phase 3 ASPIRE trial (NCT01080391) of patients with relapsed RRMM who received 1-3 prior regimens, carfilzomib plus lenalidomide and dexamethasone led to significant improvements in ORR (87\% vs 67\%; $P<0.001$ ) and median progression-free survival (PFS; 26.3 vs 17.6 months; hazard ratio [HR] 0.69 [95\% confidence interval [CI] 0.57-0.83]; $P=0.0001$ ) vs lenalidomide plus dexamethasone (Table 2) [18]. These results led to the EC authorization of carfilzomib plus lenalidomide and dexamethasone for the treatment of patients who had received $\geq 1$ prior MM therapy.

Carfilzomib has also shown greater efficacy than bortezomib in patients with MM. In the phase 3 ENDEAVOR trial (NCT01568866) of patients with RRMM who had received 1-3 prior therapies, carfilzomib plus dexamethasone demonstrated superiority over bortezomib plus dexamethasone with a significantly prolonged median PFS of 18.7 months (95\% CI, 15.6-NE) in patients in the carfilzomib-dexamethasone group vs 9.4 months [95\% CI, 8.4-10.4; HR, 0.53 (95\% CI, 0.44-0.65); $P<0.0001]$ in those in the bortezomib-dexamethasone group [19].

Interestingly, the open-label, phase 3 FOCUS trial (NCT01302392) comparing single-agent carfilzomib with low-dose dexamethasone in patients who had received $\geq 3$ prior therapies failed to meet its primary endpoint of improved OS (HR, 0.975; 95\% CI, 0.760-1.249; $P=0.4172$ ) [20]. These findings suggested that carfilzomib must be used in combination with additional agents in the RRMM setting. Of note, most control group patients (>90\%) received cyclophosphamide-dexamethasone.

\section{IMiDs}

The class of agents known as IMiDs appears to promote antitumor activity through binding to cereblon, a key component of the E3 ubiquitin ligase complex [21]. This binding promotes the ubiquitination and degradation of Ikaros and Aiolos, 2 distinct zinc-finger transcription factors that are essential to B cell development and are linked to IMiD-mediated myeloma cell death [22, 23]. Currently, lenalidomide and pomalidomide are the two IMiDs authorized for the treatment of patients with RRMM.

\section{Lenalidomide}

Lenalidomide is a thalidomide derivative that showed clinical activity in patients with refractory $\mathrm{MM}$ in phase 1 and 2 trials [24, 25]. Based on these promising findings, two large randomized phase 3 studies were initiated, one in North America (MM-009; NCT00056160) [26] and one in Europe, Australia, and Israel (MM-010; NCT00424047) [27]. These studies assessed the combination of lenalidomide plus dexamethasone vs placebo plus dexamethasone in patients with RRMM who had received $\geq 1$ prior therapy (Table 2). Both MM-009 and MM-010 demonstrated the superiority of lenalidomide plus dexamethasone vs dexamethasone alone, with very similar results. Significant improvements were observed in ORR (MM-009, 61\% vs 20\%; MM-010, $\quad 60 \% \quad$ vs $24 \% ; \quad P<0.001)$, TTP (MM-009, 11.1 vs 4.7 months; MM-010, 11.3 vs 4.7 months; $P<0.001$ ), and median OS (MM-009, 29.6 vs 20.2 months $[P<0.001]$; MM-010, not reached vs 20.6 months $[P=0.03])$. These findings led to the authorization of lenalidomide plus dexamethasone for the treatment of patients with $\mathrm{MM}$ who have received $\geq 1$ prior therapy [28]. A pooled update of the MM-009 and 
MM-010 studies showed that responses were durable and that the OS benefit was retained [29].

\section{Pomalidomide}

Pomalidomide is a third-generation IMiD agent that was recently approved by the EC for the treatment of patients with RRMM who have had $\geq 2$ prior treatments, including bortezomib and lenalidomide, and have progressive disease on treatment [30]. This approval was based on the findings from the phase $3 \mathrm{MM}-003$ study (NCT01311687), which compared pomalidomide plus low-dose dexamethasone vs high-dose dexamethasone in patients with RRMM (Table 2) [31]. ORR was higher in the pomalidomide plus dexamethasone group than in the high-dose dexamethasone group (31\% vs $10 \% ; P<0.0001)$ and median PFS was longer [4.0 vs 1.9 months; HR, $0.48 \quad$ (95\% CI, 0.39-0.60); $P<0.0001]$. Similarly, an increase in OS was observed in the pomalidomide plus low-dose dexamethasone group $[12.7$ vs 8.1 months; HR, 0.74 (95\% CI, 0.56-0.97); $P=0.0285]$.

To further evaluate the safety and efficacy of pomalidomide plus low-dose dexamethasone in this patient population, the phase $3 \mathrm{~b}$ multicenter European study STRATUS (NCT01712789) was initiated [32]. This is the largest study of pomalidomide plus low-dose dexamethasone to date, with 682 patients enrolled at the last analysis [33]. Findings were consistent with what was observed in the MM-003 study; the ORR was 33\% (median duration of response, 7.4 months) and the median PFS and OS were 4.6 and 11.9 months, respectively.

Triple-drug combinations with pomalidomide are also being assessed, given that recent studies have shown the addition of a third agent to treatment regimens leads to deeper responses in patients with RRMM. The addition of cyclophosphamide to pomalidomide plus dexamethasone was recently evaluated in a phase 2 multicenter study in patients with RRMM $(N=80)$ [34]. Patients were randomized (1:1) to receive pomalidomide-dexamethasone or pomalidomide-dexamethasone with cyclophosphamide. The triple combination of pomalidomide-cyclophosphamide -dexamethasone resulted in a higher ORR (65\% vs $39 \% ; P=0.035)$ and PFS (9.5 vs 4.4 months; $P=0.106)$ than pomalidomide-dexamethasone in patients with lenalidomide-refractory MM. A new study evaluating the combination of pomalidomide and dexamethasone with low-dose, twice-daily cyclophosphamide is currently enrolling (NCT02176213).

Pomalidomide is also being evaluated in combination with low-dose dexamethasone and bortezomib. This combination showed promising activity (ORR, 71\%) and good tolerability in a phase 1 dose-escalation study in patients with RRMM [35] and is now being assessed in the global, randomized, phase 3 MM-007 study (OPTIMISMM; NCT01734928) [36]. MM-007 is designed to compare pomalidomide plus bortezomib plus low-dose dexamethasone vs bortezomib plus dexamethasone in patients with RRMM who have received 1-3 prior lines of therapy, including lenalidomide (target enrollment 782). The primary endpoint will be PFS.

\section{Monoclonal Antibodies}

Monoclonal antibodies have shown antitumor activity in a variety of cancers. These agents selectively target markers found exclusively or predominantly on myeloma cells. In addition to targeting myeloma cells for death, they may exert immunologic control of minimal residual 
disease by acting against immunosuppressive cells such as regulatory $\mathrm{T}$ cells, regulatory $\mathrm{B}$ cells, and/or myeloid-derived suppressor cells. The two monoclonal antibodies that have received authorization from the EC are elotuzumab and daratumumab.

\section{Elotuzumab}

Elotuzumab is a monoclonal antibody directed against signaling lymphocytic activation molecule F7, a cell-surface glycoprotein expressed on natural killer cells and myeloma cells but not on normal cells, enabling selective targeting [37]. Elotuzumab can exert antimyeloma activity through activation of natural killer cells and through antibody-dependent cell-mediated cytotoxicity [38] but has no activity as a single agent [39]. However, in the phase 3 ELOQUENT-2 trial (NCT01239797), the addition of elotuzumab to the backbone of lenalidomide and dexamethasone in patients with 1-3 prior therapies led to a prolonged median PFS [19.4 vs 14.9 months; HR, 0.70 (95\% CI, 0.57-0.85); $P<0.001]$ and increased ORR (79\% vs $66 \%$; $P<0.001)$ compared with lenalidomide and dexamethasone alone (Table 2) [40]. Elotuzumab, in combination with lenalidomide and dexamethasone, received authorization on May 11, 2016, for the treatment of patients with $\mathrm{MM}$ who have received $\geq 1$ prior therapy.

Elotuzumab has also shown clinical efficacy when combined with bortezomib and dexamethasone. In an open-label phase 2 study (NCT01478048), patients with RRMM were randomized to receive elotuzumab-bortezomib-dexamethasone $(n=77) \quad$ or bortezomib-dexamethasone $(n=75)$ [41]. The triple-agent combination resulted in a greater PFS than did the bortezomib-dexamethasone combination
(9.7 vs 6.9 months). ORR was also higher in patients treated with elotuzumab-bortezomib-dexamethasone than with bortezomib-dexamethasone $(66 \%$ vs $63 \%)$, and early OS results indicated an HR of 0.61 (70\% CI, 0.43-0.85).

\section{Daratumumab}

Daratumumab is a monoclonal antibody that targets CD38, a marker that is highly expressed on myeloma cells with only minimal expression on normal lymphoid and myeloid cells [42]. Daratumumab is unique in that it can exert antimyeloma cell activity through a number of different pathways, including complement-dependent cytotoxicity, antibody-dependent cell-mediated cytotoxicity, antibody-dependent cellular phagocytosis, and apoptosis [43-45]. In contrast to elotuzumab, daratumumab has demonstrated clinical efficacy as a single agent in heavily treated patients with RRMM. In the phase 2 SIRIUS trial (NCT01985126), patients who had received $\geq 3$ prior regimens, including a PI and an IMiD, were treated with daratumumab monotherapy. In this very heavily pretreated and highly refractory population, daratumumab demonstrated an ORR of $29 \%$ with a median PFS of 3.7 months and a median OS of 17.5 months (Table 2) [46]. In the dose-escalation phase $1 / 2$ study GEN 501 (NCT00574288), daratumumab demonstrated clinical efficacy in patients with RRMM who were refractory to $\geq 2$ prior lines of therapy. In the dose-expansion part of the study, patients received $8 \mathrm{mg} / \mathrm{kg}(n=30)$ or $16 \mathrm{mg} / \mathrm{kg}(n=42)$ of daratumumab. The ORR was $36 \%$ in the cohort that received $16 \mathrm{mg} / \mathrm{kg}$ and $10 \%$ in the cohort that received $8 \mathrm{mg} / \mathrm{kg}$. The estimated median PFS was 5.6 and 2.4 months in patients who received 16 and $8 \mathrm{mg} / \mathrm{kg}$, respectively. The OS rate at 12 months was $77 \%$ in both cohorts 
[47]. An updated pooled analysis of 148 patients treated with daratumumab $16 \mathrm{mg} / \mathrm{kg}$ monotherapy has recently been published. Data were combined from part 2 of a first-in-human phase $1 / 2$ study and from a phase 2 study; $86.5 \%$ of patients were refractory to both a PI and an IMiD. The ORR was $31 \%$, which included 13 very good partial responses, 4 complete responses, and 3 stringent complete responses. The median duration of response was 7.6 months; median PFS and OS were 4.0 and 20.1 months, respectively [48]. Based on these findings, daratumumab was authorized by the EC on May 20, 2016, as a monotherapy for the treatment of patients with RRMM previously treated with a PI and an IMiD.

Daratumumab also showed synergistic antimyeloma activity in combination with lenalidomide in preclinical studies. Based on these findings, a phase $1 / 2$ study (GEN 503; NCT01615029) of daratumumab in combination with lenalidomide and low-dose dexamethasone in patients with RRMM who had $\geq 1$ prior line of therapy was initiated [49]. Daratumumab at a dose of $16 \mathrm{mg} / \mathrm{kg}$ plus lenalidomide and low-dose dexamethasone had a favorable benefit:risk profile and was associated with durable responses [50]. The ORR was $88 \%$, and the median duration of response was not reached; responses deepened over time in $61 \%$ of responders.

Given these promising results, the combination of daratumumab plus lenalidomide and dexamethasone was evaluated in the POLLUX study (NCT02076009), a phase 3, multicenter, open-label, randomized study (Table 2) [51]. In this study, 569 patients who had received $\geq 1$ prior line of therapy were randomized (1:1) to daratumumab-lenalidomide-dexamethasone or to lenalidomide-dexamethasone. The primary endpoint was PFS. Daratumumab led to a significant improvement in median PFS (63\% reduction in the risk of progression or death) and a delayed TTP compared with lenalidomide-dexamethasone alone (not reached vs 18.4 months; $P<0.0001)$. ORR was also significantly higher in patients treated with daratumumab $(93 \%$ vs $76 \% ; \quad P<0.0001)$. Neutropenia, thrombocytopenia, and anemia were the most common grade $3 / 4$ adverse events (AEs).

Daratumumab is also being evaluated in combination with bortezomib in a second randomized phase 3 study (CASTOR; NCT02136134), and findings from an interim analysis were recently reported (Table 2) [52]. Patients who had received $\geq 1$ prior line of therapy were randomized $1: 1$ to receive either daratumumab-bortezomib-dexamethasone $(n=251) \quad$ or $\quad$ bortezomib-dexamethasone $(n=247)$. Daratumumab plus bortezomib significantly improved median PFS, the primary endpoint, leading to a $61 \%$ reduction in the risk of progression or death vs bortezomib alone $(P<0.0001)$. In addition, daratumumab increased the TTP (not reached vs 7.3 months; $P<0.0001)$ as well as the ORR $(83 \%$ vs $63 \%$; $P<0.0001)$. The safety profile of the combination therapy was consistent with that of daratumumab and bortezomib, with thrombocytopenia, anemia, and neutropenia being the most common grade 3/4 AEs.

\section{Novel Agents}

As MM therapy continues to evolve at a rapid pace, a number of new agents are in clinical development. These agents include the first oral proteasome inhibitor (ixazomib) and a novel monoclonal antibody targeting CD38 (isatuximab). 


\section{Ixazomib}

Ixazomib, like bortezomib, is a boronic acid-based proteasome inhibitor, although its chemical structure and pharmacology are distinct from those of its predecessor [53, 54]. Results from the phase 3 TOURMALINE-MM1 trial (NCT01564537) demonstrated that the addition of oral ixazomib to lenalidomide and dexamethasone led to significant improvement in median PFS vs placebo plus lenalidomide and dexamethasone [20.6 vs 14.7 months; HR, 0.74 (95\% CI, 0.59-0.94); $P=0.012$ ] [55]. Ixazomib was recently approved by the US Food and Drug Administration but received a negative opinion from the Committee for Medicinal Products for Human Use on May 27, 2016.

\section{Isatuximab}

Isatuximab (formerly SAR650984) is a humanized anti-CD38 antibody that, like daratumumab, has shown clinical efficacy both as a single agent and in combination with other therapies [56]. Preliminary findings from a phase 1 study (NCT01084252) that included 35 patients with RRMM showed that isatuximab was well tolerated and induced an ORR of $24 \%$ [57]. Preliminary reports from a second phase 1 study (NCT01749969; $n=12$ ) found that the efficacy of isatuximab was enhanced when given in combination with lenalidomide and dexamethasone (ORR 58\%) [58]. Additionally, a preclinical study showed that pomalidomide increased isatuximab-induced $\mathrm{MM}$ cell killing, and that it did so more potently than lenalidomide [59]. Furthermore, enhanced antitumor activity has been demonstrated with isatuximab plus bortezomib in preclinical models [60]. Currently, isatuximab is being evaluated in patients with RRMM as combination therapy with carfilzomib (NCT02332850) and with pomalidomide and dexamethasone
(NCT02283775) in patients with RRMM. There is also an ongoing study of isatuximab plus bortezomib, cyclophosphamide, and dexamethasone in patients with newly diagnosed MM (NCT02513186).

\section{DACi for the Treatment of MM}

\section{Epigenetics as a Target in MM}

DACi prevents deacetylation, a process involved in epigenetic regulation. Several studies have suggested that targeting the epigenome may be a viable strategy in treating MM. Epigenetic modifications such as histone methylation and acetylation have been shown to affect myeloma cell biology and are important for the pathogenesis of MM [61-63]. For instance, hypermethylation of histone $\mathrm{H} 3 \mathrm{~K} 27$ by the Polycomb group proteins results in an underexpressed gene expression profile common to patients with MM [64]. Additionally, a recent study found that patients with MM had reduced expression of tumor suppressor genes due to hypermethylation of these genes, a modification that was also prognostic for reduced $O S$ in these patients [65]. Furthermore, dysregulation of histone deacetylase (HDAC) expression has also been observed in $\mathrm{MM}$ cells, with overexpression correlating with shorter survival [66].

Several preclinical studies have shown that DACi are active in MM. One study showed that a DACi (panobinostat) reactivated genes repressed by the hypermethylation of H3K27 by the Polycomb group proteins and reduced proliferation and increased apoptosis in human MM cell lines [64]. Additionally, panobinostat led to gene upregulation, reduction of tumor load, and increased OS in preclinical models [64]. Likewise, upregulation of genes following treatment of MM cell lines with DACi correlated 
with increased OS [67]. Interestingly, the antimyeloma activity of DACi was found to occur largely through inhibition of HDAC1, an event necessary for maximal MM cell death [68].

Based on these and other preclinical findings, several DACi are being evaluated in clinical studies as therapeutic options in MM. Vorinostat, a panDACi, has shown clinical efficacy in combination with bortezomib in patients with RRMM in the VANTAGE-088 phase 3 randomized study (NCT00773747) [69]. However, although vorinostat plus bortezomib significantly prolonged PFS compared with placebo, investigators did not think the difference in PFS between the two treatment groups was of clinical relevance.

Ricolinostat is a selective HDAC6 inhibitor that has demonstrated promising efficacy in patients with RRMM. Several phase $1 / 2$ studies are underway, and preliminary analyses have shown that ricolinostat has clinical activity in patients with RRMM when combined with bortezomib and low-dose dexamethasone [70], lenalidomide and dexamethasone [71], and pomalidomide and dexamethasone [72]. Additionally, its selective HDAC6 inhibition is expected to result in increased tolerability.

Panobinostat, in combination with bortezomib and dexamethasone, is the only approved DACi for the treatment of RRMM, specifically in patients who have received $\geq 2$ prior regimens including bortezomib and an IMiD. The following sections will further describe the mechanism of action of panobinostat and the efficacy and safety of this agent in this patient subpopulation.

Panobinostat: First-in-Class DACi for the Treatment of MM

Mechanism of Action Panobinostat is a potent panDACi with activity in the nanomolar range
[73] that has shown potent antitumor activity, especially when combined with other agents, such as PIs [74]. Interestingly, MM cells are particularly reliant on protein degradation due to the high production of antibodies and abnormal or mutant proteins in these cells $[13,75]$. Therefore, this synergistic anti-MM activity may be due to the complementary inhibition of protein degradation pathways, the proteasome and the aggresome. The proteasome is the main mechanism for degradation of intracellular proteins [75]. The aggresome is an alternative protein degradation pathway that appears to rely on HDAC6 for binding of the polyubiquitinated misfolded protein to dynein to facilitate transport to the lysosome [76]. Simultaneous blockade of the proteasome and the aggresome by PIs and DACi may lead to the synergistic antimyeloma activity observed with panobinostat plus bortezomib (Fig. 1a) [77]. However, there is also evidence that suggests a complementary role between PIs and DACi in epigenetic regulation as well. A study investigating the mechanism of bortezomib-induced cytotoxicity found that bortezomib downregulates the expression of class I HDAC and induces histone hyperacetylation in MM cells [78]. Additionally, HDAC1 activity negatively correlates with the antimyeloma activity of bortezomib, suggesting that bortezomib targets HDACs through a different mechanism compared with DACi [78]. Therefore, the synergy of panobinostat with bortezomib appears to occur through two distinct mechanisms, epigenetic alteration and protein metabolism (Fig. 1b).

\section{Dosing and Administration The} recommended starting dose is $20 \mathrm{mg}$ taken orally once every other day for three doses per week in week 1 and 2 of a 3 -week cycle for eight 
A
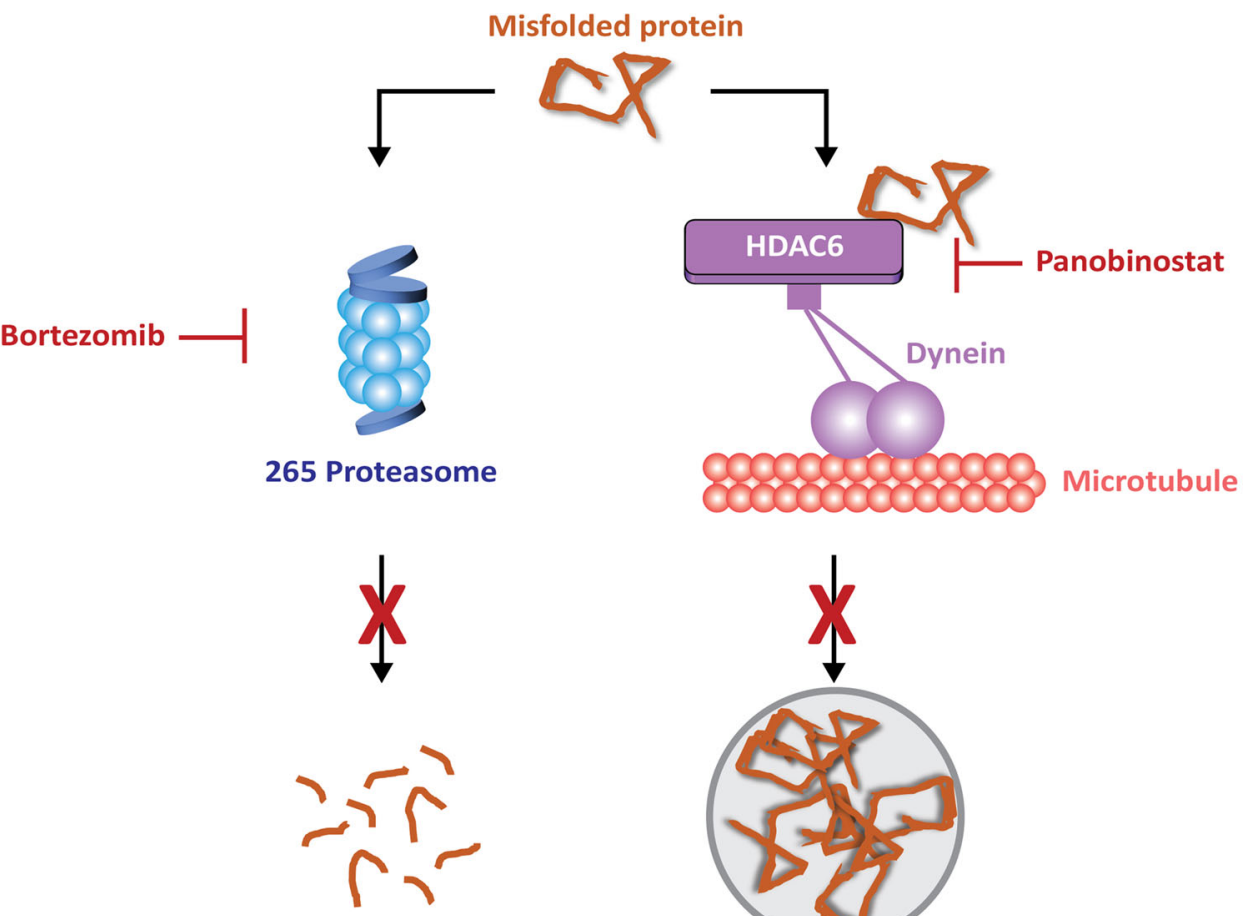

Protein degradation

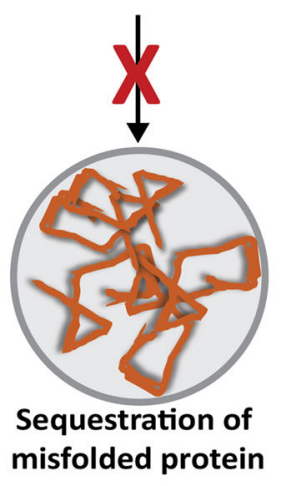

B
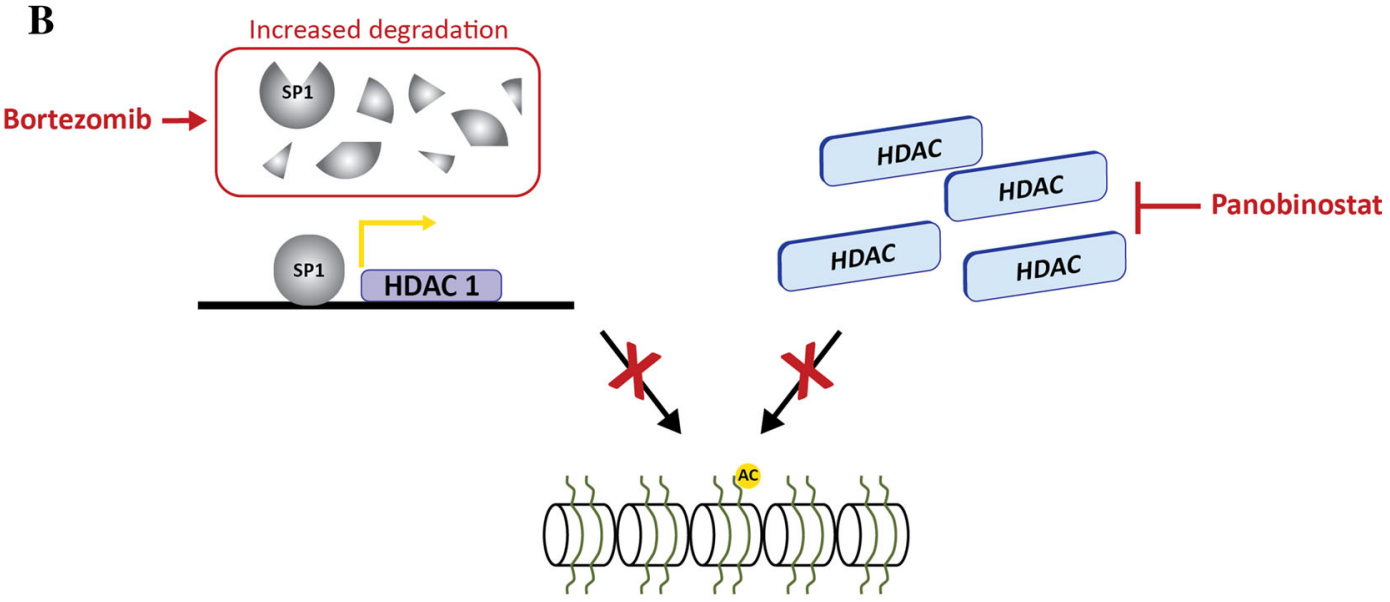

Hypoacetylation of histones

Fig. 1 Panobinostat mechanism of action: synergy with bortezomib. a Dual blockade of proteasomes and aggresome pathway. b Synergistic impact on epigenetics. HDAC histone deacetylase, SP1 Simian virus 40 promotor factor 1

cycles. Treatment should be continued for an additional eight cycles if the patient shows clinical benefit and no severe AEs. If clinically necessary, dose reductions of panobinostat should proceed in 5-mg intervals, but panobinostat should be discontinued if a dose reduction below $10 \mathrm{mg}$ three times per week is required. Similarly, bortezomib dose reductions (in $25 \%$ decrements) are advised if clinically necessary. 


\section{Panobinostat Efficacy and Safety: A Focus on the EU-Indicated Subpopulation}

Panobinostat, in combination with bortezomib and dexamethasone, was well tolerated and significantly improved PFS in patients with relapsed or RRMM in the pivotal phase 3 PANORAMA 1 study (NCT01023308; $N=768$ ) [79]. In this study, patients with relapsed or RRMM (excluding those with bortezomib-refractory or primary-refractory $\mathrm{MM}$ ) who had received 1 to 3 prior regimens were randomized 1:1 to receive 21-day cycles of placebo or panobinostat (20 mg orally on days $1,3,5,8,10$, and 12), both in combination with bortezomib $\left(1.3 \mathrm{mg} / \mathrm{m}^{2}\right.$ intravenously on days $1,4,8$, and 11) and dexamethasone (20 mg orally on days $1,2,4,5,8,9,11$, and 12). The study met its primary endpoint of PFS [79].

A subgroup analysis of PANORAMA 1 patients who had received $\geq 2$ prior regimens, including bortezomib and an IMiD, demonstrated that panobinostat $(n=75)$ provided this patient population with a PFS benefit of 7.8 months vs placebo $(n=74)$ (Tables 2, 3) [80]; median PFS was 12.5 months (95\% CI, 7.3-14.0) in the panobinostat group and 4.7 months (95\% CI, 3.7-6.1) in the placebo group [HR, 0.47 (95\% CI, 0.31-0.72)] (Fig. 2). Similarly, patients who had received $\geq 2$ prior regimens including bortezomib and an IMiD had a higher ORR with panobinostat than with placebo $(59 \%$ vs $39 \% ; \quad P=0.01703)$ (Table 3) [80]. Likewise, panobinostat led to more high-quality responses than did placebo (complete or near-complete response rate, 22\% vs $8 \% ; P=0.02296)$. Median duration of response was also higher in the panobinostat group [12.0 months (95\% CI, 9.7-13.4)] vs the placebo group [7.0 months (95\% CI, 4.9-13.4)]. Notably, in patients treated with panobinostat, median PFS was similar between this patient subgroup and the overall PANORAMA 1 patient population (12.5 vs 12.0 months, respectively), whereas heavily pretreated patients who received bortezomib-dexamethasone alone had a substantially reduced PFS (4.7 vs 8.1 months, respectively). This suggests that the efficacy of the panobinostatbortezomib-dexamethasone combination is somewhat resistant to the negative impacts of prior treatment. Analysis of the treatment-free interval (TFI), defined as the mean PFS less the mean duration of treatment, demonstrated that TFI was more than double in the panobinostat group vs the placebo group (4.7 vs 1.9 months) among patients with $\geq 2$ prior regimens including bortezomib and an IMiD, implying the potential for enhanced off-treatment benefit in the panobinostat group [80]. In this subgroup, the recent final OS analysis of PANORAMA 1 presented at the 2015 American Society of Hematology annual meeting demonstrated a 6.0-month OS benefit favoring the panobinostat group, although the HR did not favor either treatment group [median OS: panobinostat group, 25.5 months; placebo group, 19.5 months; HR, 1.01 (95\% CI, 0.68-1.50)] [81].

Overall, the safety profile in this subgroup was similar to that in the overall PANORAMA 1 population (Table 4) [79, 80]. The most common hematologic AEs in patients who had received $\geq 2$ prior regimens including bortezomib and an IMiD were thrombocytopenia [panobinostat, 97\% (grade 3/4, 68\%); placebo, 90\% (grade 3/4, 44\%)] and neutropenia [panobinostat, $83 \%$ (grade 3/4, $40 \%$ ); placebo, $45 \%$ (grade 3/4, 16\%)]. These rates were comparable to those of thrombocytopenia and neutropenia in the overall population. The most common nonhematologic AEs in this patient subgroup were diarrhea [panobinostat, 76\% (grade 3/4, $33 \%$ ); placebo, $47 \%$ (grade $3 / 4,15 \%$ )] and 
Table 3 Efficacy of panobinostat in patients with relapsed or relapsed and refractory multiple myeloma who have received $\geq 2$ prior regimens, including bortezomib (BTZ) and an immunomodulatory drug [80]

\begin{tabular}{lll}
\hline & PAN-BTZ-Dex & Pbo-BTZ-Dex \\
\hline Overall response rate (95\% CI), \% & $59(47-70)$ & $39(28-51)$ \\
$P$ value & $P=0.01703$ & \\
Complete or near-complete response rate (95\% CI), \% & $22(13-33)$ & $8(3-17)$ \\
$P$ value & $P=0.02296$ & \\
Duration of response, median (95\% CI), mo & $12.0(9.7-13.4)$ & $7.0(4.9-13.4)$ \\
Time to response, median (95\% CI), mo & $1.5(1.4-2.6)$ & NE (2.1-NE) \\
Time to progression, relapse, or death, median (95\% CI), mo & $12.7(8.3-14.2)$ & $5.0(3.8-6.8)$ \\
Progression-free survival, median (95\% CI), mo & $12.5(7.3-14.0)$ & $4.7(3.7-6.1)$ \\
Hazard ratio (95\% CI) & $0.47(0.31-0.72)$ & \\
Treatment-free interval (mean progression-free survival - mean duration & 4.7 & 1.9 \\
$\quad$ of response), mo & & \\
\hline
\end{tabular}

Dex dexamethasone, $N E$ not evaluable, $P A N$ panobinostat, $P b o$ placebo, $B T Z$ bortezomib, $M O$ month, $C I$ confidence interval

fatigue or asthenia [panobinostat, 60\% (grade $3 / 4,26 \%$ ); placebo, $49 \%$ (grade $3 / 4,14 \%$ )], with rates comparable to those seen in the overall population.

The proportion of on-treatment deaths was similar between the two treatment groups among patients who received $\geq 2$ prior regimens including bortezomib and an IMiD (panobinostat, 6.9\%; placebo, 6.8\%) [80]. Deaths due to progressive disease among patients in this group were slightly higher in the placebo group (panobinostat, 0\%; placebo, $2.7 \%$ ). The proportion of on-treatment deaths was slightly higher in the panobinostat group of the overall PANORAMA 1 population than in the placebo group or the subgroup of patients who received $\geq 2$ prior regimens including bortezomib and an IMiD [79, 80]. The proportion of deaths due to progressive disease in the overall population was similar to that observed in the heavily pretreated subgroup.
Importantly, despite toxicities being observed with the panobinostat-bortezomibdexamethasone regimen, analysis of health-related quality of life showed no appreciable difference in patient-reported outcomes between treatment groups in the subgroup of patients who had received $\geq 2$ prior regimens including bortezomib and an IMiD [82]. At week 24, similar scores were reported for the Functional Assessment of Cancer Therapy/Gynecologic Oncology Group-Neurotoxicity (panobinostat group vs placebo group, 31.75 vs 33.57), European Organisation for Research and Treatment (EORTC) 20-item disease symptom (23.84 vs 16.55), and EORTC 30-item core quality-of-life global health status (53.82 vs 58.05) questionnaires. Overall, these results suggested that the addition of panobinostat to the established bortezomib-dexamethasone regimen did not profoundly impact health-related quality of life. 


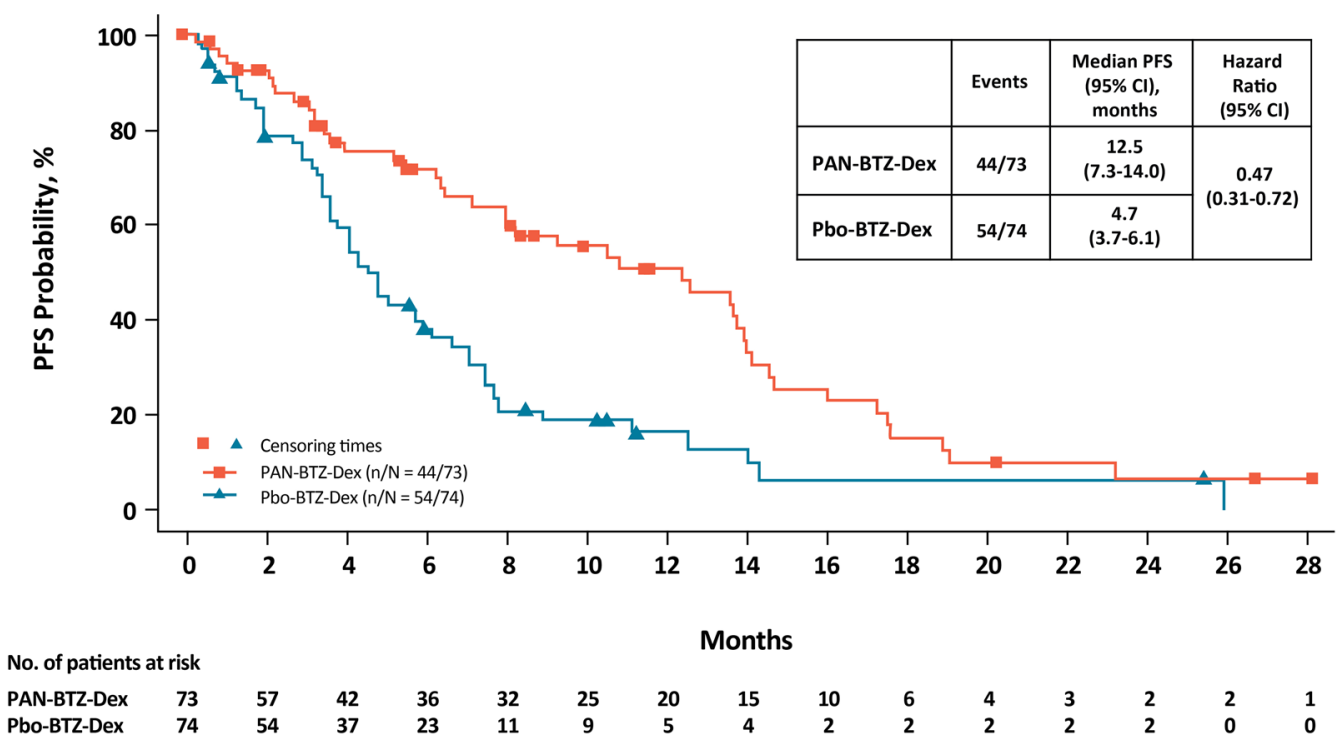

Fig. 2 Progression-free survival among patients in the PANORAMA 1 study who received $\geq 2$ prior regimens, including bortezomib and an immunomodulatory agent [80]. BTZ bortezomib, Dex dexamethasone, PAN

Based on these results and the enhanced benefit:risk profile of the panobinostat-bortezomib-dexamethasone regimen in this subpopulation with few treatment options, on August 28, 2015, the EC authorized panobinostat in combination with bortezomib and dexamethasone for the treatment of relapsed or RRMM in patients who have received $\geq 2$ prior regimens, including bortezomib and an IMiD (Fig. 3). Concerns were raised during the authorization process about the safety and tolerability of the panobinostat-bortezomib-dexamethasone regimen, and thus a risk management plan was devised to ensure that the regimen was provided as safely as possible and included guidance for management of key AEs [83]. On January 27, 2016, NICE also recommended panobinostat in combination with bortezomib and dexamethasone for adult patients with RRMM who have received $\geq 2$ prior regimens including bortezomib and an IMiD [84]. The panobinostat, Pbo placebo, PFS progression-free survival, $C I$ confidence interval. This research was originally published in Blood. Richardson [80]. (C) The American Society of Hematology

Appraisal Committee thoroughly reviewed the efficacy and safety of the panobinostat plus bortezomib and dexamethasone combination and concluded that the AEs associated with the treatment were manageable in clinical practice. The Committee also compared the cost-effectiveness of panobinostat-bortezomibdexamethasone with that of lenalidomidedexamethasone and determined that the cost per quality-adjusted life year for the panobinostat combination was within the range considered to be cost-effective. Therefore, the drug was launched in the United Kingdom in February.

\section{Management of Key AEs Associated with}

Panobinostat-Bortezomib-Dexamethasone

Therapy

Thrombocytopenia A decrease in platelet count is an AE associated with both bortezomib and panobinostat due to the inhibition of megakaryocyte maturation and 


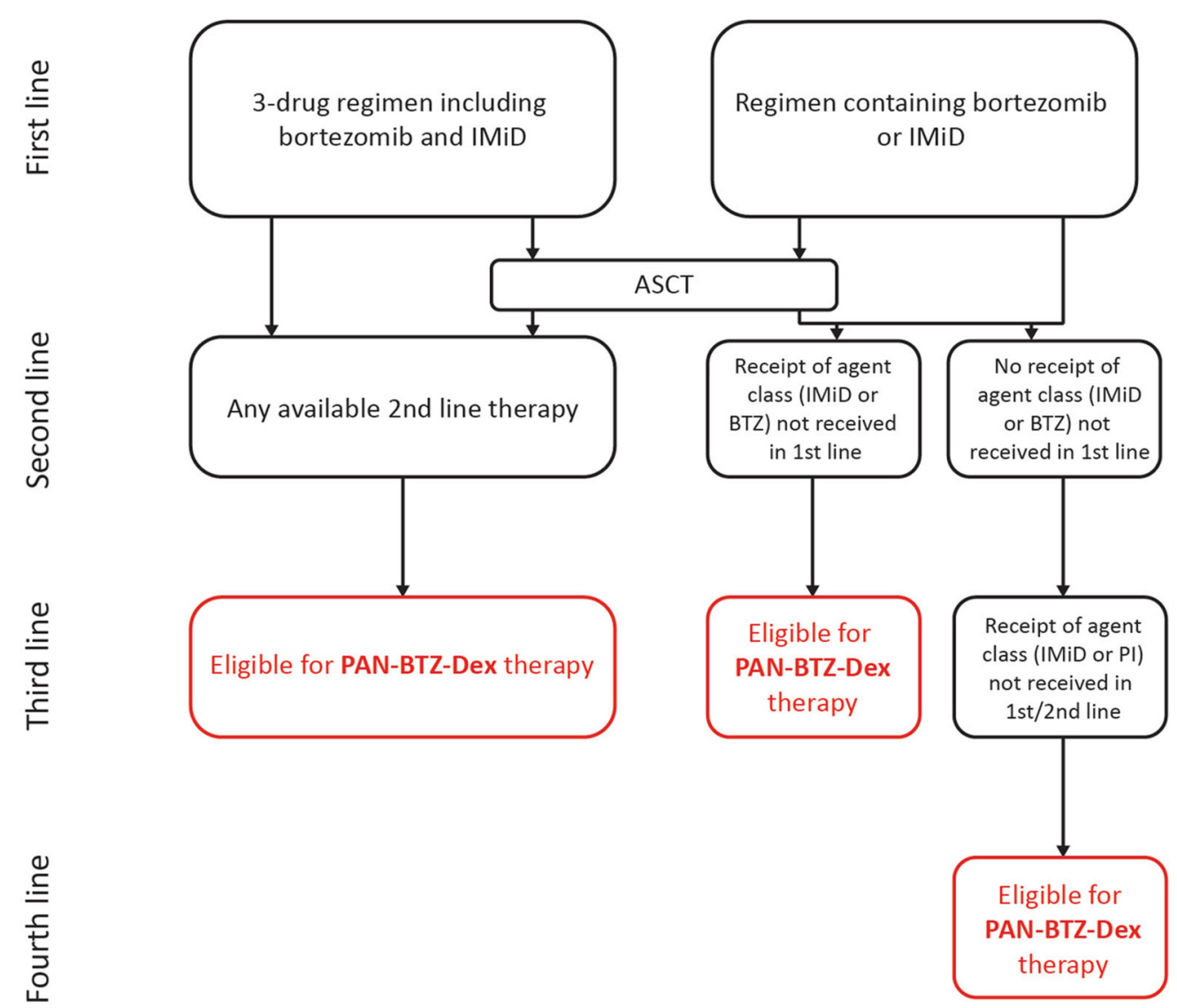

Fig. 3 Treatment algorithm for PAN based on current European Commission authorization. ASCT autologous stem cell transplant, BTZ bortezomib, Dex

the reduced release of proplatelets $[85,86]$. Although platelets typically rebound during the off-treatment week [79], the risk of severe bleeding events remains in some patients. Identifying patients at increased risk of severe bleeding prior to starting panobinostat-bortezomib-dexamethasone and monitoring of platelet levels regularly during the course of therapy are recommended. Platelet counts should be monitored at least weekly in patients with $\geq$ grade 3 thrombocytopenia (platelet count $<50 \times 10^{9} / \mathrm{L}$ ) [87].

In general, dose adjustment (delay or reduction) is typically sufficient for proper dexamethasone, IMiD immunomodulatory drug, $P I$ proteasome inhibitors, $P A N$ panobinostat

management of patients who develop on-treatment thrombocytopenia. Grade 3 thrombocytopenia with bleeding or grade 4 thrombocytopenia (platelet count $<25 \times 10^{9} / \mathrm{L}$ ) should be managed with interruption of panobinostat and bortezomib dosing [87]. Once thrombocytopenia recovers to $\leq$ grade 2 (platelet count $\geq 50 \times 10^{9} / \mathrm{L}$ ), panobinostat and bortezomib dosing should be resumed. Panobinostat should be restarted at a reduced dose. Bortezomib should be restarted at the same dose if only 1 dose was omitted or a reduced dose if $\geq 2$ doses were omitted. Physicians should consider platelet transfusions for patients who experience 
Table 4 Safety summary of panobinostat in patients with relapsed or relapsed and refractory multiple myeloma who have received $\geq 2$ prior regimens, including bortezomib (BTZ) and an immunomodulatory drug [80]

\begin{tabular}{|c|c|c|c|c|}
\hline & \multicolumn{2}{|c|}{ PAN-BTZ-Dex $(n=72)$} & \multicolumn{2}{|c|}{ Pbo-BTZ-Dex $(n=73)$} \\
\hline & All grade & Grade 3/4 & All grade & Grade 3/4 \\
\hline \multicolumn{5}{|c|}{ Hematologic laboratory abnormality, $n$ (\%) } \\
\hline Thrombocytopenia & $70(97)$ & $49(68)$ & $65(90)$ & $32(44)$ \\
\hline Leukopenia & $60(83)$ & $15(21)$ & $40(55)$ & $8(11)$ \\
\hline Lymphopenia & $60(83)$ & $35(49)$ & $56(77)$ & $36(49)$ \\
\hline Neutropenia & $60(83)$ & $29(40)$ & $33(45)$ & $12(16)$ \\
\hline Anemia & $42(58)$ & $15(21)$ & $42(58)$ & $15(21)$ \\
\hline \multicolumn{5}{|l|}{ Nonhematologic adverse events, $n$ (\%) } \\
\hline Diarrhea & $55(76)$ & $24(33)$ & $34(47)$ & $11(15)$ \\
\hline Fatigue or asthenia & $43(60)$ & $19(26)$ & $36(49)$ & $10(14)$ \\
\hline Peripheral neuropathy & $42(58)$ & $12(17)$ & $39(53)$ & $5(7)$ \\
\hline Nausea & $27(38)$ & $8(11)$ & $16(22)$ & $1(1)$ \\
\hline Peripheral edema & $16(22)$ & $2(3)$ & $11(15)$ & 0 \\
\hline Vomiting & $18(25)$ & $4(6)$ & $7(10)$ & $2(3)$ \\
\hline Hypokalemia & $18(25)$ & $15(21)$ & $12(16)$ & $5(7)$ \\
\hline Decreased appetite & $16(22)$ & $1(1)$ & $10(14)$ & 0 \\
\hline Upper respiratory tract infection & $21(29)$ & $4(6)$ & $12(16)$ & 0 \\
\hline Pyrexia & $10(14)$ & 0 & $10(14)$ & $3(4)$ \\
\hline Constipation & $19(26)$ & $2(3)$ & $20(27)$ & $2(3)$ \\
\hline Cough & $19(26)$ & 0 & $15(21)$ & 0 \\
\hline Abdominal pain & $17(24)$ & $1(1)$ & $8(11)$ & $2(3)$ \\
\hline
\end{tabular}

Dex dexamethasone, $P A N$ panobinostat, $P b o$ placebo, $B T Z$ bortezomib

severe thrombocytopenia. If thrombocytopenia does not resolve or the patient requires multiple platelet transfusions, treatment should be discontinued.

Diarrhea Frequent loose or watery stool was common with panobinostat-bortezomibdexamethasone treatment and can be associated with dehydration and electrolyte imbalances. Patients should be advised to initiate antidiarrheal medication and contact their physician at the first sign of abdominal cramping, loose stool, or diarrhea. Patients should also contact their physician if signs of dehydration are present. Prophylactic antiemetic therapy could be considered, but avoidance of those that cause electrocardiographic changes is warranted. Periodic monitoring of salt levels and fluid balance is advised [87].

Physicians should manage grade 2 diarrhea (4-6 stools/day above baseline) with 
interruption of panobinostat and bortezomib dosing until resolution to $\leq$ grade 1 diarrhea [87]. Panobinostat should be restarted at the same dose, while bortezomib should be restarted at a reduced dose or changed to once-weekly dosing. Grade 3 diarrhea $(\geq 7$ stools/day above baseline) should be managed with interruption of panobinostat and bortezomib dosing until resolution to $\leq$ grade 1 diarrhea. Panobinostat should be restarted at a reduced dose, and bortezomib should also be restarted at a reduced dose or changed to once-weekly dosing. For patients who experienced grade 4 diarrhea (life-threatening consequences), treatment should be discontinued.

Other Notable AEs Patients at risk of infection should be treated prior to receiving the regimen [87]. White blood cell counts should be monitored regularly, and any developing infection should be treated promptly [87]. Panobinostat therapy should be avoided in patients at risk for QTc prolongation or receiving concomitant medications known to prolong the QT interval that cannot be stopped [87]. Electrocardiographic monitoring should be conducted regularly, along with fluid balance and salt monitoring. If QT prolongation occurs, panobinostat should be stopped until QT prolongation resolves. AEs may be more severe in patients over 65 years of age, and thus more frequent monitoring, particularly of blood cell counts and gastrointestinal toxicity, may be warranted, and dose reductions should be used as needed. Further research into optimization of the dose, schedule, and route of administration of panobinostat and bortezomib is important and may improve AEs, including fatigue and peripheral neuropathy.

\section{The Role of Panobinostat in the Current MM Treatment Armamentarium}

There are a number of factors that help guide treatment decisions in patients with RRMM, including patient age, comorbidities, performance status, prior treatment received, toxicities developed during prior treatment, and response to prior therapy [88]. However, following a short response on a therapy, a change to an agent with a new mechanism of action is often advised. Recent evidence also suggests that the addition of a third agent to backbone regimens can provide additional benefit over two-drug combinations in patients with RRMM [89]. As outlined previously, the current MM treatment landscape in the European Union comprises two main backbone regimens, PIs and IMiDs. However, as most patients will eventually relapse after or become refractory to the currently available agents, there is a substantial unmet need for agents with novel mechanisms of action in these patients.

Panobinostat, in combination with bortezomib and dexamethasone, is authorized for patients with relapsed or RRMM who have received $\geq 2$ prior treatment regimens including bortezomib and an IMiD, and it is one of the first agents with a new mechanism of action to be authorized for $\mathrm{MM}$ in over a decade. The addition of panobinostat to bortezomib and dexamethasone in the label subpopulation led to a significant increase in the rate of high-quality responses (complete or near-complete response) compared with placebo-bortezomib-dexamethasone $(22 \%$ vs $8 \% ; P=0.02296)$ [80]. The median PFS in patients treated with panobinostat was similar between the label subpopulation and the overall PANORAMA 1 patient population, suggesting that patients derive benefit from panobinostat 
regardless of prior treatment [79, 80]. Additionally, panobinostat has demonstrated the potential to recapture responses in patients who are refractory to bortezomib [90]. In the single-arm, phase 2 PANORAMA 2 study (NCT01083602), adding panobinostat to a bortezomib-dexamethasone regimen resulted in an ORR of $34.5 \%$ and a clinical benefit rate of $52.7 \%$ in 55 heavily pretreated patients who had received $\geq 2$ prior lines of therapy, including an IMiD, and who were refractory to bortezomib-based therapy. Median PFS was 5.4 months, and median OS was 17.5 months [91]. A previous study by the International Myeloma Working Group found that among patients who are refractory to bortezomib and have relapsed following, have MM refractory to, or are ineligible to receive an IMiD, median OS and event-free survival were 9 months and 5 months, respectively [7]. Thus, the findings from the PANORAMA 2 study suggest that panobinostat may have a role in the management of bortezomib-refractory patients.

Panobinostat is also being investigated in the relapsed and refractory setting in other novel combinations with PIs (carfilzomib and ixazomib) and IMiDs (lenalidomide and thalidomide). In addition, panobinostat is being studied in the newly diagnosed setting in combination with lenalidomide, bortezomib or carfilzomib, and dexamethasone. Use of these panobinostat-based combinations is not yet approved in Europe.

\section{CONCLUSION}

Overall, panobinostat is likely to be an important new option for patients who have aggressive disease previously treated with PIs and IMiDs. Findings from the PANORAMA clinical program show that panobinostat can recapture responses, increase response quality, and overcome the negative impact of prior treatment on patient outcomes. Improvement in the quality of response has been recently linked to better patient outcomes [92] and may represent an important goal in the treatment of patients with RRMM. Targeted therapies, such as a DACi like panobinostat, will allow patients to achieve maximal responses and prolonged survival, therefore proving to be instrumental therapeutic options in the $\mathrm{MM}$ treatment armamentarium.

\section{ACKNOWLEDGMENTS}

No funding or sponsorship was received for this study, publication of this article or the open access fee. We thank Michael Demars, $\mathrm{PhD}$, and Karen Chinchilla, PhD, of ArticulateScience LLC for editorial support, funded by Novartis Pharmaceuticals. During the peer-review process, the manufacturer of the agent under review was offered an opportunity to comment on the article. No changes to the original content were made as a result of this. All named authors meet the International Committee of Medical Journal Editors (ICMJE) criteria for authorship for this manuscript, take responsibility for the integrity of the work as a whole, and have given final approval to the version to be published.

Disclosures. Jesus F San-Miguel has served on advisory committees or review panels for Celgene, Novartis, Janssen, Amgen, Millennium, Onyx, Bristol-Myers Squibb, and Merck Sharpe \& Dohme. Hermann Einsele has received grants from Janssen, Celgene, Novartis, Bristol-Myers Squibb, and Millennium. Philippe Moreau has received personal fees from 
Novartis, Janssen, Celgene, Takeda, and Bristol-Myers Squibb.

Compliance with Ethics Guidelines. This article is based on previously conducted studies, and does not involve any new studies of human or animal subjects performed by any of the authors.

Open Access. This article is distributed under the terms of the Creative Commons Attribution-NonCommercial 4.0 International License (http://creativecommons.org/licenses/ by-nc/4.0/), which permits any noncommercial use, distribution, and reproduction in any medium, provided you give appropriate credit to the original author(s) and the source, provide a link to the Creative Commons license, and indicate if changes were made.

\section{REFERENCES}

1. Palumbo A, Anderson K. Multiple myeloma. N Engl J Med. 2011;364:1046-60.

2. Rajkumar SV, Dimopoulos MA, Palumbo A, et al. International Myeloma Working Group updated criteria for the diagnosis of multiple myeloma. Lancet Oncol. 2014;15:e538-48.

3. International Agency for Research on Cancer. Estimated cancer incidence, mortality, prevalence and disability-adjusted life years (DALYs) worldwide in 2012. GLOBOCAN. 2012. Accessed 25 Jan 2016.

4. Ferlay J, Steliarova-Foucher E, Lortet-Tieulent J, et al. Cancer incidence and mortality patterns in Europe: estimates for 40 countries in 2012. Eur J Cancer. 2013;49:1374-403.

5. Kumar SK, Rajkumar SV, Dispenzieri A, et al. Improved survival in multiple myeloma and the impact of novel therapies. Blood. 2008;111:2516-20.

6. Cornell RF, Kassim AA. Evolving paradigms in the treatment of relapsed/refractory multiple myeloma: increased options and increased complexity. Bone Marrow Transpl. 2016;51:479-91.
7. Kumar SK, Lee JH, Lahuerta JJ, et al. Risk of progression and survival in multiple myeloma relapsing after therapy with IMiDs and bortezomib: a multicenter International Myeloma Working Group study. Leukemia. 2012;26:149-57.

8. Kumar SK, Therneau TM, Gertz MA, et al. Clinical course of patients with relapsed multiple myeloma. Mayo Clin Proc. 2004;79:867-74.

9. Thalidomide (thalidomide capsules) [summary of product characteristics]. Uxbridge: Celgene Europe Limited; 2016.

10. Adams J. The proteasome: a suitable antineoplastic target. Nat Rev Cancer. 2004;4:349-60.

11. Obeng EA, Carlson LM, Gutman DM, Harrington WJ Jr, Lee KP, Boise LH. Proteasome inhibitors induce a terminal unfolded protein response in multiple myeloma cells. Blood. 2006;107:4907-16.

12. Kortuem KM, Stewart AK. Carfilzomib. Blood. 2013;121:893-7.

13. Hideshima $T$, Richardson PG, Anderson KC. Mechanism of action of proteasome inhibitors and deacetylase inhibitors and the biological basis of synergy in multiple myeloma. Mol Cancer Ther. 2011;10:2034-42.

14. LeBlanc R, Catley LP, Hideshima $\mathrm{T}$, et al. Proteasome inhibitor PS-341 inhibits human myeloma cell growth in vivo and prolongs survival in a murine model. Cancer Res. 2002;62:4996-5000.

15. Richardson PG, Sonneveld P, Schuster MW, et al. Bortezomib or high-dose dexamethasone for relapsed multiple myeloma. $\mathrm{N}$ Engl J Med. 2005;352:2487-98.

16. Demo SD, Kirk CJ, Aujay MA, et al. Antitumor activity of PR-171, a novel irreversible inhibitor of the proteasome. Cancer Res. 2007;67:6383-91.

17. Meng L, Mohan R, Kwok BH, Elofsson M, Sin N, Crews CM. Epoxomicin, a potent and selective proteasome inhibitor, exhibits in vivo antiinflammatory activity. Proc Natl Acad Sci USA. 1999;96:10403-8.

18. Stewart AK, Rajkumar SV, Dimopoulos MA, et al. Carfilzomib, lenalidomide, and dexamethasone for relapsed multiple myeloma. $\mathrm{N}$ Engl J Med. 2015;372:142-52.

19. Dimopoulos MA, Moreau P, Palumbo A, et al. Carfilzomib and dexamethasone versus bortezomib and dexamethasone for patients with relapsed or refractory multiple myeloma 
(ENDEAVOR): a randomised, phase 3, open-label, multicentre study. Lancet Oncol. 2016;17:27-38.

20. Ludwig H, Masszi T, Petrucci M, et al. Carfilzomib (K) vs low-dose corticosteroids and optional cyclophosphamide (cy) in patients (pts) with relapsed and refractory multiple myeloma (RRMM): results from a phase 3 study (FOCUS). Ann Oncol. 2014;25 (abstract LBA28).

21. Zhu YX, Braggio E, Shi CX, et al. Cereblon expression is required for the antimyeloma activity of lenalidomide and pomalidomide. Blood. 2011;118:4771-9.

22. Lu G, Middleton RE, Sun H, et al. The myeloma drug lenalidomide promotes the cereblon-dependent destruction of Ikaros proteins. Science. 2014;343:305-9.

23. Kronke J, Udeshi ND, Narla A, et al. Lenalidomide causes selective degradation of IKZF1 and IKZF3 in multiple myeloma cells. Science. 2014;343:301-5.

24. Richardson PG, Schlossman RL, Weller E, et al. Immunomodulatory drug CC-5013 overcomes drug resistance and is well tolerated in patients with relapsed multiple myeloma. Blood. 2002;100:3063-7.

25. Richardson PG, Blood E, Mitsiades CS, et al. A randomized phase 2 study of lenalidomide therapy for patients with relapsed or relapsed and refractory multiple myeloma. Blood. 2006;108:3458-64.

26. Weber DM, Chen C, Niesvizky $R$, et al. Lenalidomide plus dexamethasone for relapsed multiple myeloma in North America. N Engl J Med. 2007;357:2133-42.

27. Dimopoulos $M$, Spencer A, Attal $M$, et al. Lenalidomide plus dexamethasone for relapsed or refractory multiple myeloma. $\mathrm{N}$ Engl J Med. 2007;357:2123-32.

28. Revlimid (lenalidomide) [summary of product characteristics]. Uxbridge: Celgene Europe Limited; 2015.

29. Dimopoulos MA, Chen C, Spencer A, et al. Long-term follow-up on overall survival from the MM-009 and MM-010 phase III trials of lenalidomide plus dexamethasone in patients with relapsed or refractory multiple myeloma. Leukemia. 2009;23:2147-52.

30. Imnovid (pomalidomide) [summary of product characteristics]. Uxbridge: Celgene Europe Limited; 2016.

31. San Miguel J, Weisel K, Moreau $P$, et al. Pomalidomide plus low-dose dexamethasone versus high-dose dexamethasone alone for patients with relapsed and refractory multiple myeloma (MM-003): a randomised, open-label, phase 3 trial. Lancet Oncol. 2013;14:1055-66.

32. Dimopoulos MA, Weisel KC, Cavo M, et al. The STRATUS trial (MM010): a single-arm phase 3b study of pomalidomide plus low-dose dexamethasone (POM + LoDEX) in refractory or relapsed and refractory multiple myeloma. J Clin Oncol. 2014;32(suppl) (abstract TPS8625).

33. Dimopoulos MA, Palumbo A, Corradini P, et al. An updated analysis of the STRATUS trial (MM-010): safety and efficacy of pomalidomide plus low-dose dexamethasone (POM + LoDEX) in patients (pts) with relapsed/refractory multiple myeloma (RRMM). Blood. 2015;126:4225.

34. Baz RC, Martin TG 3rd, Lin HY, et al. Randomized multicenter phase 2 study of pomalidomide, cyclophosphamide, and dexamethasone in relapsed refractory myeloma. Blood. 2016;127:2561-8.

35. Richardson PG, Hofmeister C, Raje NS, et al. MM005: phase 1 trial of pomalidomide (POM), bortezomib (BORT), and low-dose dexamethasone (LoDEX [PVD]) in lenalidomide (LEN)-refractory and proteasome inhibitor (PI)-exposed myeloma. J Clin Oncol. 2014;32(suppl) (abstract 8589).

36. Richardson PG, Bensmaine A, Doerr T, Wang J, Zaki $\mathrm{MH}, \mathrm{MM007}$ Study Investigators. MM007: a phase 3 trial comparing the efficacy and safety of pomalidomide (POM), bortezomib (BORT), and low-dose dexamethasone (LoDEX [PVD]) versus BORT and LoDEX (VD) in subjects with relapsed or refractory multiple myeloma (RRMM). J Clin Oncol. 2015;33(suppl) (abstract TPS8610).

37. Hsi ED, Steinle R, Balasa B, et al. CS1, a potential new therapeutic antibody target for the treatment of multiple myeloma. Clin Cancer Res. 2008;14:2775-84.

38. Collins SM, Bakan CE, Swartzel GD, et al. Elotuzumab directly enhances NK cell cytotoxicity against myeloma via CS1 ligation: evidence for augmented NK cell function complementing ADCC. Cancer Immunol Immunother. 2013;62:1841-9.

39. Zonder JA, Mohrbacher AF, Singhal S, et al. A phase 1 , multicenter, open-label, dose escalation study of elotuzumab in patients with advanced multiple myeloma. Blood. 2012;120:552-9.

40. Lonial S, Dimopoulos M, Palumbo A, et al. Elotuzumab therapy for relapsed or refractory multiple myeloma. N Engl J Med. 2015;373:621-31. 
41. Jakubowiak A, Offidani M, Pegourie B, et al. Randomized phase 2 study: elotuzumab plus bortezomib/dexamethasone vs bortezomib/ dexamethasone for relapsed/refractory MM. Blood. 2016;127:2833-40.

42. Lin P, Owens R, Tricot G, Wilson CS. Flow cytometric immunophenotypic analysis of 306 cases of multiple myeloma. Am J Clin Pathol. 2004;121:482-8.

43. de Weers M, Tai YT, van der Veer MS, et al. Daratumumab, a novel therapeutic human CD38 monoclonal antibody, induces killing of multiple myeloma and other hematological tumors. J Immunol. 2011;186:1840-8.

44. Overdijk MB, Verploegen $\mathrm{S}$, Bogels $\mathrm{M}$, et al. Antibody-mediated phagocytosis contributes to the anti-tumor activity of the therapeutic antibody daratumumab in lymphoma and multiple myeloma. MAbs. 2015;7:311-21.

45. Jansen JHM, Boross P, Overdijk MB, van Bueren JJL, Parren PWHI, Leusen JHW. Daratumumab, a human CD38 antibody induces apoptosis of myeloma tumor cells via Fc receptor-mediated crosslinking. Blood. 2012;120:2974.

46. Lonial S, Weiss BM, Usmani SZ, et al. Daratumumab monotherapy in patients with treatment-refractory multiple myeloma (SIRIUS): an open-label, randomised, phase 2 trial. Lancet. 2016;387:1551-60.

47. Lokhorst HM, Plesner T, Laubach JP, et al. Targeting CD38 with daratumumab monotherapy in multiple myeloma. N Engl J Med. 2015;373:1207-19.

48. Usmani SZ, Weiss BM, Plesner $\mathrm{T}$, et al. Clinical efficacy of daratumumab monotherapy in patients with heavily pretreated relapsed or refractory multiple myeloma. Blood. 2016;128:37-44.

49. Plesner T, Arkenau HT, Lokhorst HM, et al. Safety and efficacy of daratumumab with lenalidomide and dexamethasone in relapsed or relapsed, refractory multiple myeloma. Blood. 2014;124:84.

50. Plesner $\mathrm{T}$, Arkenau $\mathrm{H}$, Gimsing $\mathrm{P}$, et al. Daratumumab in combination with lenalidomide and dexamethasone in patients with relapsed or relapsed and refractory multiple myeloma: updated results of a phase $1 / 2$ study (GEN503). Blood. 2015;126:507.

51. Dimopoulos MA, Oriol A, Nahi $\mathrm{H}$, et al. An open-label, randomised phase 3 study of daratumumab, lenalidomide, and dexamethasone (DRD) versus lenalidomide and dexamethasone (RD) in relapsed or refractory multiple myeloma (RRMM): POLLUX. EHA Annual Meeting; June
9-12, 2016; Copenhagen, Denmark (abstract LB238).

52. Palumbo A, Chanan-Khan A, Weisel K, et al. Phase 3 randomised controlled study of daratumumab, bortezomib and dexamethasone versus bortezomib and dexamethasone in patients with relapsed or refractory multiple myeloma: CASTOR. EHA Annual Meeting; June 9-12, 2016; Copenhagen, Denmark (abstract LB2236).

53. Lee EC, Fitzgerald M, Bannerman $B$, et al. Antitumor activity of the investigational proteasome inhibitor MLN9708 in mouse models of B-cell and plasma cell malignancies. Clin Cancer Res. 2011;17:7313-23.

54. Kupperman E, Lee EC, Cao Y, et al. Evaluation of the proteasome inhibitor MLN9708 in preclinical models of human cancer. Cancer Res. 2010;70:1970-80.

55. Moreau P, Masszi T, Grzasko N, et al. Ixazomib, an investigational oral proteasome inhibitor (PI), in combination with lenalidomide and dexamethasone (IRd), significantly extends progression-free survival (PFS) for patients (pts) with relapsed and/or refractory multiple myeloma (RRMM): the phase 3 TOURMALINE-MM1 study. Blood. 2015;126:727.

56. van de Donk NW, Janmaat ML, Mutis T, et al. Monoclonal antibodies targeting CD38 in hematological malignancies and beyond. Immunol Rev. 2016;270:95-112.

57. Martin TG, Hsu K, Strickland SA, Glenn MJ, Mikhael J, Charpentier E. A phase 1 trial of SAR650984, a CD38 monoclonal antibody, in relapsed or refractory multiple myeloma. J Clin Oncol. 2014;32:5s(suppl) (abstract 8532).

58. Martin T, Hsu K, Charpentier E, et al. A phase Ib dose escalation trial of SAR650984 (anti-CD-38 $\mathrm{mAb}$ ) in combination with lenalidomide and dexamethasone in relapsed/refractory multiple myeloma. J Clin Oncol. 2014;32(5 suppl) (abstract 8512).

59. Jiang H, Acharya C, An G, et al. SAR650984 directly induces multiple myeloma cell death via lysosomal-associated and apoptotic pathways, which is further enhanced by pomalidomide. Leukemia. 2016;30:399-408.

60. Wetzel M, Nicolazzi C, Vallée F, et al. SAR650984: characterization of a potent phase I humanized antiCD38 antibody for the treatment of multiple myeloma and other hematologic malignancies. Cancer Res. 2013;73:4735. 
61. Smith EM, Boyd K, Davies FE. The potential role of epigenetic therapy in multiple myeloma. $\mathrm{Br} \mathrm{J}$ Haematol. 2010;148:702-13.

62. Maes K, Menu E, Van Valckenborgh E, Van Riet I, Vanderkerken K, De Bruyne E. Epigenetic modulating agents as a new therapeutic approach in multiple myeloma. Cancers (Basel). 2013;5:430-61.

63. Walker BA, Wardell CP, Chiecchio L, et al. Aberrant global methylation patterns affect the molecular pathogenesis and prognosis of multiple myeloma. Blood. 2011;117:553-62.

64. Kalushkova A, Fryknas M, Lemaire $M$, et al. Polycomb target genes are silenced in multiple myeloma. PLoS ONE. 2010;5:e11483.

65. Kaiser MF, Johnson DC, Wu P, et al. Global methylation analysis identifies prognostically important epigenetically inactivated tumor suppressor genes in multiple myeloma. Blood. 2013;122:219-26.

66. Mithraprabhu S, Kalff A, Chow A, Khong T, Spencer A. Dysregulated class I histone deacetylases are indicators of poor prognosis in multiple myeloma. Epigenetics. 2014;9:1511-20.

67. Moreaux J, Reme T, Leonard W, et al. Gene expression-based prediction of myeloma cell sensitivity to histone deacetylase inhibitors. $\mathrm{Br} \mathrm{J}$ Cancer. 2013;109:676-85.

68. Mithraprabhu S, Khong T, Jones SS, Spencer A. Histone deacetylase (HDAC) inhibitors as single agents induce multiple myeloma cell death principally through the inhibition of class I HDAC. Br J Haematol. 2013;162:559-62.

69. Dimopoulos M, Siegel DS, Lonial S, et al. Vorinostat or placebo in combination with bortezomib in patients with multiple myeloma (VANTAGE 088): a multicentre, randomised, double-blind study. Lancet Oncol. 2013;14:1129-40.

70. Raje N, Vogl D, Hari P, et al. ACY-1215, a selective histone deacetylase (HDAC) 6 inhibitor: interim results of combination therapy with bortezomib in patients with multiple myeloma (MM). Blood. 2013;122(21):759 (abstract 759).

71. Yee AJ, Voorhees PM, Bensinger $\mathrm{W}$, et al. Ricolinostat (ACY-1215), a selective HDAC6 inhibitor, in combination with lenalidomide and dexamethasone: results of a phase $1 \mathrm{~b}$ trial in relapsed and relapsed refractory multiple myeloma. Blood. 2014;124:4772 (abstract 4772).

72. Raje N, Bensinger W, Lebovic D, et al. Ricolinostat (ACY-1215) the first selective HDAC6 inhibitor in combination with pomalidomide and dexamethasone in patients with relapsed \& refractory multiple myeloma: phase $1 \mathrm{~b} \&$ early phase 2 results. Haematologica. 2015;100:86.

73. Atadja P. Development of the pan-DAC inhibitor panobinostat (LBH589): successes and challenges. Cancer Lett. 2009;280:233-41.

74. Ocio EM, Vilanova D, Atadja P, et al. In vitro and in vivo rationale for the triple combination of panobinostat (LBH589) and dexamethasone with either bortezomib or lenalidomide in multiple myeloma. Haematologica. 2010;95:794-803.

75. Chari A, Mazumder A, Jagannath S. Proteasome inhibition and its therapeutic potential in multiple myeloma. Biologics. 2010;4:273-87.

76. Kawaguchi Y, Kovacs JJ, McLaurin A, Vance JM, Ito A, Yao TP. The deacetylase HDAC6 regulates aggresome formation and cell viability in response to misfolded protein stress. Cell. 2003;115:727-38.

77. Catley L, Weisberg E, Kiziltepe T, et al. Aggresome induction by proteasome inhibitor bortezomib and alpha-tubulin hyperacetylation by tubulin deacetylase (TDAC) inhibitor LBH589 are synergistic in myeloma cells. Blood. 2006;108:3441-9.

78. Kikuchi J, Wada T, Shimizu R, et al. Histone deacetylases are critical targets of bortezomib-induced cytotoxicity in multiple myeloma. Blood. 2010;116:406-17.

79. San-Miguel JF, Hungria VT, Yoon SS, et al. Panobinostat plus bortezomib and dexamethasone versus placebo plus bortezomib and dexamethasone in patients with relapsed or relapsed and refractory multiple myeloma: a multicentre, randomised, double-blind phase 3 trial. Lancet Oncol. 2014;15:1195-206.

80. Richardson PG, Hungria VT, Yoon SS, et al. Panobinostat plus bortezomib and dexamethasone in relapsed/relapsed and refractory myeloma: outcomes by prior treatment. Blood. 2016;127:713-21.

81. San Miguel JF, Hungria VT, Yoon SS, et al. Final analysis of overall survival from the phase 3 PANORAMA 1 trial of panobinostat plus bortezomib and dexamethasone in patients with relapsed or relapsed and refractory multiple myeloma. Blood. 2015;126:3026.

82. Richardson PG, Hungria V, Yoon SS, et al. Patient reported outcomes (PROs) of multiple myeloma (MM) patients from the PANORAMA-1 study who have received at least two prior regimens including 
bortezomib and an immunomodulatory agent. Haematologica. 2016;101(s1):786.

83. European Medicines Agency. Summary of the Farydak European Public Assessment Report. http:// www.ema.europa.eu/ema/index.jsp?curl=pages/medi cines/human/medicines/003725/human_med_00189 5.jsp\&mid=WC0b01ac058001d124. Accessed 24 Aug 2016.

84. National Institute for Health and Care Excellence. Panobinostat for treating multiple myeloma after at least 2 previous treatments. https://www.nice.org. uk/guidance/ta380. Accessed 11 July 2016.

85. Bishton MJ, Harrison SJ, Martin BP, et al. Deciphering the molecular and biologic processes that mediate histone deacetylase inhibitor-induced thrombocytopenia. Blood. 2011;117:3658-68.

86. Giver CR, Jaye DL, Waller EK, Kaufman JL, Lonial S. Rapid recovery from panobinostat (LBH589)-induced thrombocytopenia in mice involves a rebound effect of bone marrow megakaryocytes. Leukemia. 2011;25:362-5.

87. Farydak (panobinostat) [summary of product characteristics]. Surrey: Novartis Pharmaceuticals UK Ltd; 2016.

88. Dimopoulos MA, Richardson PG, Moreau P, Anderson KC. Current treatment landscape for relapsed and/or refractory multiple myeloma. Nat Rev Clin Oncol. 2015;12:42-54.

89. Garderet L, Iacobelli S, Moreau P, et al. Superiority of the triple combination of bortezomib-thalidomide-dexamethasone over the dual combination of thalidomide-dexamethasone in patients with multiple myeloma progressing or relapsing after autologous transplantation: the MMVAR/IFM 2005-04 randomized phase III trial from the Chronic Leukemia Working Party of the European Group for Blood and Marrow Transplantation. J Clin Oncol. 2012;30:2475-82.

90. Richardson PG, Schlossman RL, Alsina M, et al. PANORAMA 2: panobinostat in combination with bortezomib and dexamethasone in patients with relapsed and bortezomib-refractory myeloma. Blood. 2013;122:2331-7.

91. Richardson PG, Schlossman RL, Alsina M, et al. Time to event analyses in PANORAMA 2: a phase 2 study of panobinostat, bortezomib, and dexamethasone in patients with relapsed and bortezomib-refractory multiple myeloma. Blood. 2013;122(21) (abstract 1970).

92. Lonial S, Anderson KC. Association of response endpoints with survival outcomes in multiple myeloma. Leukemia. 2014;28:258-68. 